\title{
Gadolinium Use in Spine Pain Management Procedures for Patients with Contrast Allergies: Results in 527 Procedures
}

\author{
Yair Safriel · Roberto Ang · Muhammed Ali
}

Published online: 26 June 2009

(C) Springer Science+Business Media, LLC and the Cardiovascular and Interventional Radiological Society of Europe (CIRSE) 2009

\section{Retraction to: Cardiovasc Intervent Radiol}

(2007) 31:325-331

DOI 10.1007/s00270-007-9192-5

By this notice, the Editors of CardioVascular and Interventional Radiology retract from publication the following article: "Gadolinium Use in Spine Pain Management Procedures for Patients with Contrast Allergies: Results in 527
Procedures" by Yair Safriel, Roberto Ang, Muhammed Ali, published in CVIR online October 16, 2007, DOI: 10.1007/s00270-007-9192-5.

Portions of this paper were originally published by Safriel Y, Ali M, Hayt M, Ang R (2006) "Gadolinium Use in Spine Procedures for Patients with Allergy to Iodinated Contrast-Experience of 127 Procedures." Am J Neuroradiol 27:1194-1197.

The online version of the original article can be found under doi: 10.1007/s00270-007-9192-5.

Y. Safriel $(\bowtie)$

Neuroradiology Section, Department of Radiology,

Yale University School of Medicine, 333 Cedar Street,

New Haven, CT 06520, USA

e-mail: safriel@yale.edu

Y. Safriel

Radiology Associates of Clearwater, Clearwater, FL, USA

Y. Safriel

Pharmascan Clinical Trials, New York, NY, USA

R. Ang

Center for Diagnostic Imaging, St. Cloud, MN, USA

M. Ali

Kaiser Permanente Woodland Hills Medical Center,

Woodland Hills, CA, USA 